\title{
SALIENCE EFFECT ON THE PROCESSING OF IDIOMS IN L1: EVIDENCE FROM MALAY SIMPULAN BAHASA
}

\author{
Radina Mohamad Deli \\ Centre for Language Studies, Universiti Malaysia Sarawak \\ mdradina@unimas.my
}

\begin{abstract}
Experimental investigations into figurative language processing have received little attention for languages other than English and several major European languages. Research on the Malay language, in particular, has been very limited. This study thus aimed to investigate the figurative language processing of familiar Malay idioms by L1 native speakers. Familiarity or salience is hypothesised as having a dominating effect in the processing of idiom meaning. This means, regardless of context or other possible factors, salience is said to determine processing advantage. A total of 24 participants completed a timed lexical-decision task after listening to idiomatic stimuli. Eight highly familiar idioms embedded in neutral sentences were used as auditory stimuli, and were paired visually together with either their figurative or literal meaning as target words. Results revealed a similar processing speed for responses to both literal and idiomatic meanings. Hence, it was concluded that the salience levels of both meanings are balanced in line with the Graded Salience Hypothesis.
\end{abstract}

Keywords: figurative language processing, salience, timed lexical-decision, Graded Salience Hypothesis

\section{Introduction}

For over four decades, figurative language has been studied widely in the area of experimental psycholinguistics mainly involving English and other European languages. The unique property of figurative language for generally having nonliteral meanings is the factor driving research interests into how it is processed in the human mind. Idioms, in particular, are amongst those widely investigated because of its importance and abundance in human interaction. This, however, is limited to languages with existing psycholinguistic resources such as English as opposed to other languages that have only recently received attention for studies pertaining to language processing. 
An idiom is defined as an expression whose actual meaning does not always come from the meaning of its individual components (Cooper, 1999). An example of this is the meaning of idiom to kick the bucket which is to die; its actual meaning cannot be derived from either the words kick or bucket from the idiom. The equivalent of English idioms in the Malay language is known as simpulan bahasa - a figurative phrase that is similar in concept to its English counterparts (CharterisBlack, 2002). However, while English idioms vary in length, Malay idioms are typically made up of two to three words that are semantically different from the intended figurative meaning. This distinctive quality of figurative meanings has prompted research into how they are processed in the first (L1) and second language (L2). A number of models, thus, have been developed to contest issues in idiom comprehension including compositionality (Bobrow \& Bell, 1973; Swinney \& Cutler, 1979), modularity versus parallelism (Cacciari \& Tabossi, 1988; Tittone \& Connine, 1999) and literality (Gibbs, 1984), amongst other things.

Fundamentally, three classes of theories exist to account for idiom comprehension and its representation in the human mind. The first one advocates the non-compositional view of idiom comprehension and consists of first generation theories. According to these theories, idioms are processed as single units - similar to "long words" (Bobrow \& Bell, 1973; Gibbs, 1980; Swinney \& Cutler, 1979). Thus, it is assumed that there is a separate storage for the figurative meaning of an idiom and the literal meaning of its individual words. As an example, for the idiom kick the bucket, its actual meaning to die and its literal interpretation to strike a bucket with the foot, are stored separately. These earlier models, however, differ in their stand on which type of meaning, whether literal or idiomatic, is activated first and whether context plays a role in early activation. The second class of theory takes the compositional view of idiom processing in which the internal semantic structure of the idiom is considered crucial for understanding meaning (Abel, 2003; Nunberg, 1978). Finally, the third class, which takes into account both non-compositional and compositional views, is aptly known as the Hybrid theory (Tittone \& Connine, 1999). It is assumed that idioms are stored as both single word-combinations and "compositional word sequences". The Hybrid theory is thus considered superior to its predecessors because it takes into account the issue of idiom decomposability and akin to the Configuration Model (Cacciari \& Tabossi, 1988), it allows for the simultaneous activation of literal and figurative meanings in idiom comprehension.

Another hybrid theory is the Graded Salience Hypothesis (Giora, 1997, 1999; Giora et al., 2007), which is lexicon-based and assumes the priority of salience in a graded manner for activation of idiom meaning from salient, less salient, to not salient. Also known as the familiarity model, it proposes that due to the salient property of certain idioms, their meanings will be activated first even before the meaning of each word constituent whether or not supporting context is available asserting secondary role of context. This model therefore suggests that lexical access is direct and exhaustive - having multiple-meaning activation but ordered based on salience (Giora et al., 2007). This means that word meanings are directly accessed via the mental lexicon and despite the availability or the appropriateness of context, all possible meanings of a word or a phrase get activated. The activation however is based on a hierarchy of salience - with the more salient meanings enjoying faster 
access. Thus, in the case of idioms, the model disregards the view of compositionality or analyzability of their meanings and denies any competition between literal and figurative interpretations.

Researches in L1 idiom processing mainly involve European languages and very few East Asian languages, namely, Chinese and Japanese. Contributions from the latter though have been relatively recent. For the Malay language, however, idiom processing is an underexplored field in psycholinguistic studies. In fact, studies in the field of language processing for Malay as L1 in general have witnessed a slow progression. The main reason for this is the lack of fundamental knowledge in experimental psycholinguistics such as in word databasing. A very limited number of "psycholinguistically-driven" databases exist to document Malay words and lexicon (e.g. Lee, Rickard Liow, \& Wee, 2007; Mohamad Deli, Kamil, Mustafa \& Sarbini-Zin, 2013; Mohamad Deli, Mustafa, \& Sarbini-Zin, 2012; Pareira, Rickard Liow, \& Mohd Saniff, 1992; Yap, Rickard Liow, Jalil, \& Faizal, 2010;).

Additionally, research on cognitive processes involving Malay as L1 has been rather limited and pertains to spelling in children (see Jalil \& Rickard Liow, 2008) and adult bilingual reading (see Batemanazana, Jaafar, \& Salehuddin, 2014). There are also those on reading Malay words in Arabic script (e.g., Salehuddin, 2013, Salehuddin \& Winskel, 2015). Furthermore, although online experimental techniques such as reaction time (RT), eye-tracking, and Event-Related Potentials (ERP) are hardly new in the area of experimental psycholinguistics, they are more often utilised by psychologist and cognitive scientists to measure behaviour beyond linguistic abilities. This is particularly true in the case of studies conducted on Malay participants. In order to fill this gap, this study therefore aimed to investigate the L1 processing of familiar idiomatic phrases or simpulan bahasa in standard Malay (also known as bahasa Melayu). Specifically, this study will examine the effect of salience on the processing of familiar idioms in the absence of context.

It is thus hypothesised that salience or familiarity has a dominating effect on the processing of idiom meanings in the absence of context. The figurative meaning of idioms will be activated first upon hearing the idioms due to their high salient status in the mental lexicon of Malay speakers in line with Giora's (2003) findings. The hypothesis thus rejects the competition for the activation of meaning based on literality (literal versus figurative meanings). Consequently, RT measures should be faster when salient idiomatic target words are encountered as compared to nonsalient literal target words. If, however, the RTs for the literal and figurative meanings are similar, this is still in line with the Graded Salience Hypothesis based on Giora's (1997) earlier findings of a possible balance in their salience levels; that both meanings are considered highly familiar.

\section{Literature Review}

Idiomatic expressions have been the subject of interest among linguists mainly in studies involving comprehension and proficiency. In language processing research, initial studies on idioms have dealt primarily with the figurative versus the literal interpretation of meaning. One of the most influential models of idiom comprehension is Bobrow and Bell's (1973) "idiom list hypothesis". Commonly 
known as the literal first hypothesis, it claims that the processing and representation of idioms is comparable to those of long words; that is, each idiom is processed as a single phrasal unit. In addition, it is argued that idioms are stored separately from literal words in the mental lexicon. Idiom processing typically comprises the initial literal analysis, followed by the rejection of the interpretation and finally, the retrieval of the idiom's true meaning.

Likewise, Swinney and Cutler's (1979) "lexical representation hypothesis" proposes that idioms are represented and processed similar to morphologically complex words. However, unlike the "idiom list hypothesis", the activation of the literal meaning and retrieval of the figurative one are done simultaneously as soon as the first word of the idiomatic expression is encountered. Since the retrieval of figurative meaning takes less time, it would overrule literal meaning activation, and therefore would be activated first. This view is also consistent with the noncompositional theory of idiom representation, and suggests the existence of a separate mental list for an idiom's figurative meaning (Weinreich, 1969, as cited in Abel, 2003). Gibbs' "Direct Access Hypothesis" $(1986,2002)$ takes a similar view of idioms being processed as singular phrasal units. However, it suggests that the figurative meaning can be accessed without the initial activation of the literal one. This model takes the context-based approach and further claimed that the presence of appropriate context will aid the processing of idiomatic meaning over the literal one.

Cacciari and Tabossi (1988) proposed another significant model for idiom processing based on the recognition of an "idiomatic key" - a point where an expression becomes recognisable as idiomatic. The "configuration hypothesis" assumes that individual words and their literal meanings are similarly activated until the "key" is encountered to prompt the idiomatic configuration. At this point, the figurative meaning is accessed while the literal meaning is discarded. This means that depending on where the "key" is placed within a sentence, either meaning may be activated first. The result from the lexical decision task conducted, however, revealed similar activation for both meanings after 300ms delay. Cacciari and Tabossi argued that the delay may have provided the opportunity for ambiguity resolution to take place. Nonetheless, the claims were made in the absence of context to support either interpretation. In line with the Hybrid Model, this model disregards the idea of a strict division between literal and figurative meanings (Tittone \& Connine, 1999).

In the field of figurative language processing, arguments mainly revolve around the issue of literality and the effect of context on comprehension. The Graded Salience Hypothesis (Giora, 1997, 1999; Giora \& Fein, 1999a, b; Giora, 2003), a lexicon-based theory, proposes that "salience" of idiom meaning determines early activation of meaning, overruling the effect context and denying any competition for literality. In fact, unlike first generation models, the Graded Salience Hypothesis (GSH) does not posit any "processing" division between literal and non-literal language. The only reasoning involving literality within this model is the claim that the processing of a familiar idiom in a figurative-supporting context should be faster than that of its literal counterpart in a literal-supporting context. For example, the processing of kick the bucket is faster if the supporting context involves death- 
related matters, as compared to processing the literal meaning of kicking a bucket if the context supports the actual action related to kicking. This is a logical argument given that the idiomatic phrase is one with high salience value.

"Salient" meanings refer to "coded meanings foremost on our mind due to conventionality, frequency, familiarity, or prototypicality" (Giora 2003, p. 10). Accordingly, idiomatic targets related to the figurative interpretation of familiar idioms should be activated early via direct search in the mental lexicon because they are more salient than the phrase's literal meaning. Van de Voort and Vonk (1985, as cited in Giora, 2003) also found familiar idioms with salient idiom meanings being processed idiomatically in an automated manner. As for context effect, the GSH postulates an existing but secondary role for it in the processing of salient idioms. In the early stages of processing, the salient figurative meanings will be activated regardless of context; whether it supports the figurative meaning or otherwise. Giora (1997) found salient metaphoric targets or meanings being activated and having equal reading times when presented in either literal or metaphorical context. As for less familiar meanings, they are always processed longer than salient meanings. Thus, the familiar idiom to kick the bucket would prompt the salient idiomatic meaning to die in both literal and figurative biasing contexts, and is processed faster than its literal counterpart to strike the bucket forcefully with the foot.

However, there could be an exception to this when salience for both meanings is balanced or of similar levels. In this case, processing times for both figurative and literal meanings could be equal. This was demonstrated in Giora and Fein's (1999a) study in which the salient figurative and literal interpretations of familiar metaphors were found to be similarly activated in both contexts. In general, the GSH adheres to the rule of modularity in lexical access; in that "lexical access is encapsulated from contextual contexts" (Gibbs, Wilson, \& Bryant, 2012, p. 470). So, therefore, it claims that although context may play a role in idiom interpretation, this is over-ruled by the superiority of salience (Giora \& Fein, 1999b). Even if it may help to enhance the meaning of a word or phrase, it is incapable of suppressing the activation of several meanings that are similarly salient. This is illustrated as follows:

... I needed money, so I went to the bank, the prior occurrence of the word money may speed up activation of the financial institution meaning of bank. In standing on the riverbank I saw some fish, river may facilitate activation of riverbank meaning of bank. However, although it may enhance the less salient riverside meaning bank, it may not prevent activation of its more salient, financial meaning on its encounter. (Giora \& Fein, 1999b, p. 243)

Presently, the literature on idiomatic processing has yet to cover Malay idiomatic phrases or L1 processing by Malay speakers. In fact, Malay figurative language items as a whole may have yet to receive any attention in the field of language processing. Most research on Malay figurative language involves peribahasa. Although peribahasa can be translated to mean proverbs, it can sometimes be considered as a bigger term for other sub-categories of figurative expressions such as idioms, metaphors and adages in Malay (see Ishak \& Mansor, 
2011). A few works have categorised and discussed the structure or category of peribahasa in Malay (e.g., Hassan \& Mohd, 1993; Zahid, 1998). Many researches explored similar themes investigating peribahasa as part of the Malay culture or identity (e.g., Daud, 2001; Mat Hassan \& Hamzah, 2010; Salleh, 1999). Lim (2003), in particular, explored the Malay reasoning and emotion in his extensive work on peribahasa. Ishak and Mansor (2011) looked specifically into the use of simpulan bahasa in contemporary advertisements. Others have ventured into inter-language translation of simpulan bahasa (Abd. Rahman \& Mohd. Norwawi, 2013; CharterisBlack, 2003). One study looked at the relationship between self-consciousness and perception of strategies used in learning Malay idioms in L2 (Mohd Amin, Meor Hissan, \& Abdul Rahman, 2013).

Idioms or simpulan bahasa evidently forms a significant part of the figurative language repertoire of Malay and have been studied extensively in the larger field of linguistics with a majority focusing on the aspects of language, culture and identity. Thus, taking into consideration the lack of experimental investigations into figurative processing of Malay idioms, the study hypothesises that salience has a dominating effect in the processing of familiar idioms by L1 speakers in the absence of context (neutral context). This means that idiomatic meanings rather than literal meanings of idioms will be evoked first due to familiarity or salience. However, if processing times for both interpretations are found to be similar, this could be interpreted as a show of "balance" in the salience levels for both literal and figurative targets used in this study. This possible finding will still be in line with Giora's (1997) conclusion and does not in any way nullify the claim that all language items are processed in a similar manner until "salience" is at stake prompting direct look up and activation of all salient meanings despite incompatibility with prior contexts.

\section{Methodology}

Thirty-six young Malay adults (12 males) aged between 20 and 37 participated in the experimental study which employed the cross-modal priming method. Participants were given tokens for their participation in a timed lexical decision task. Equipped with a laptop, a headphone and a gamepad, participants were required to listen to 18 sentences that were embedded with idioms. While listening to each sentence, they had to decide, as quickly as possible, whether or not a single word appearing on-screen was a real or a nonsense word. In addition, they were required to answer a simple yes-no comprehension question after each listening to ensure they have understood the sentences. A language background questionnaire was also distributed before the experimental trials. Eventually, only RT data from 24 participants were used due to the following reasons: 1 . two out of three who were left-handed gave inconsistent answers to the comprehension questions, 2 . four sets of RT data were not recorded due to technical problems, 3. five participants gave at least one wrong answer to the comprehension questions, and 4. one participant repeated the experiment half-way through because of some computer error.

A total of 18 auditory stimuli and their corresponding target words presented visually were used in the study. However, only eight auditory stimuli 
containing idioms and their corresponding target items were the actual items used for investigation. For this study, the simpulan bahasa used are considered highly familiar (Mohamad Deli et al., 2013). They were compiled, selected and categorised according to familiarity and meaningfulness in a small study, as there is no available psycholinguistic database for idioms available for Malay. Malay idioms, unlike English idioms, are typically made up of two to three words; however, for this study, only 2-word phrases were selected for consistency. The idioms were characterised as non-compositional - the meaning of each component in all the idioms do not contribute to the idioms' actual meaning. The classification was based on a small survey done on idiom compositionality (Mohamad Deli at al., 2013) and presented in neutral contexts or without prior contexts. Ten filler stimuli items and their corresponding words or nonsense words were mixed with the actual stimuli and target words. The sentences were read by a native Malay speaker and recorded in a recording studio to ensure audibility. The sound files were edited and fine-tuned using "GoldWave" audio editing software.

The eight actual visual targets were displayed on the computer screen and placed at the offset position immediately after the utterance of the final word of each idiomatic phrase. As an example, for the auditory sentence Erin dan keluarganya telah [makan angin]* di Bali dua hari lepas, participants would either encounter the visual target cuti which is related to the figurative meaning of the idiom to mean vacation, or sejuk which is related to the literal meaning of the final word in the idiomatic expression to mean cold. As for each filler item (word or nonsense word), it was assigned to appear randomly after the utterance of any one word within each sentence. The cross-modal priming method such as the one used in this study is a common method utilized for investigating figurative language processing (e.g., Cacciari \& Tabossi, 1988; Cieślicka, 2006; Ghareb-Ali, 2008).

The target words were selected by the researchers - who are native speakers of Malay - based on their own knowledge of word meaning. As an example, for the idiom makan angin (to eat wind), the selected target words were either sejuk (cold), a word related to the literal meaning of angin (wind), or cuti (vacation), a word related or similar to the figurative meaning of the idiom. The words were controlled for approximate familiarity levels for both types of target words, length, and proximity to the intended meaning. Since there is no available psycholinguistic database for Malay word familiarity, a post investigation was done on the frequency of the target words. Data was taken from the Malay Lexicon Project (Yap et al., 2010) to assess the "compatibility" of the literal-figurative target pairings.

Using the DMDX display software, the experiment was programmed in such a way that the auditory stimuli was presented first followed by the visual presentation of the target words and simultaneous measurement of response time at predetermined positions. The target words were set to be displayed on the screen for $2500 \mathrm{~ms}$ and subjects had to make a lexical decision within this period after listening to a string of sentence by pressing the YES or NO button on a game pad (coloured green and red respectively). For filler sentences, random word and nonword targets were displayed at various positions. After each listening, participants were required to answer the corresponding YES-NO comprehension questions to 
test their understanding of previously presented sentences. The experimental session which was divided into two parts included one rest pause in between the two and this was controlled by the participants themselves. Each session took approximately 10 minutes to complete. The independent variable is "target type" which consisted of two levels - idiomatic and literal, and the dependent variable is the participant's reading or reaction time (RT). SPSS was used to analyse the RT data.

\section{Results and findings}

The RT data were analysed as a two-leveled (literal or idiomatic) variable using the paired sample test. The data were initially cleaned for reaction times of more than $2500 \mathrm{~ms}$. Although the average normal adult reading speed is $2000 \mathrm{~ms}$, it was felt that there was a need for an addition of $500 \mathrm{~ms}$ to account for the complexity and difficulty of the cross-modal priming method experienced by the participants. As shown in Table 1, the mean for RT to literal targets is $976.24 \mathrm{~ms}$ and $1001.57 \mathrm{~ms}$ for their figurative counterparts. Although the former is shorter by approximately 25 milliseconds, the test revealed no significant difference $(p>0.05)$ between both RTs.

Table 1

Mean for reaction times to literal and idiomatic targets

\begin{tabular}{lr}
\hline Target types & \multicolumn{1}{c}{ Mean } \\
\hline Literal & $976.24 \mathrm{~ms}$ \\
Figurative & $1001.57 \mathrm{~ms}$ \\
\hline
\end{tabular}

Results suggest that the speeds for processing the literal and figurative idiom meanings were equal in neutral context or in the absence of context to support either meaning. For example, the idiom target for cahaya mata which is anak (child) and the literal target lihat (see) may both be deemed salient in the mental lexicon, and therefore were not in competition with each other. This early activation for both meanings also suggests that there is no separate mode or storage for processing literal or figurative language. The activation of meaning is thus determined by the salience feature regardless of context or in the case of this study in neutral context. The finding from this study therefore confirms the claim of a modular lexical access determined by salience, consistent with Giora's (2003) claim. Because context was not manipulated, our hypothesis assumes that salience play a determining role in the interpretation of familiar idioms in the absence of context. Although different than most of Giora's experimental item design in which often ambiguous phrases were used for instance, metaphors or ironies with valid literal and figurative meanings, the present finding is still consistent with the claim of saliency superiority - at least over literality. Since the literal targets were constructed for the meaning of the final word of the idiom phrase, it is possible then to assume that even if some of the idiomatic phrase is not "meaningful" or not necessarily interpretable (e.g. naik angin - wind arising) the salient effect of the literal target word was still activated early. The only explanation for this then is a 
"balanced" salience levels for both meanings - actual idiom meaning and actual word or phrase (literal) meaning.

With the assumption that context does not determine lexical access until after salience, the idiomatic stimuli was placed within neutral context, or in other words, without context. Although context may have early effects on the activation of meanings, it can never supersede the role of salience, familiarity or conventionality. It is important to note that although it is predicted that figurative reading would override the literal reading because of its high salience, the hypothesis does not rule out the likelihood of a balanced salience level and therefore, direct and simultaneous access for both meanings regardless of literality. The hypothesis in fact asserts that meanings of words or phrases that are salient do not necessarily have to be literal or figurative; instead salience reflects on the most commonly and conventionally used words or phrases.

Giora and Fein (1999a) conducted three off-line experiments to investigate the effect of salience on the processing of familiar metaphor. They predicted that both salient literal and figurative meanings of the metaphors will be initiated irrespective of the types of context. Using a word fragment completion test, activation of meaning was measured and revealed that more salient meanings (both literal and figurative) were processed faster than less salient meanings. In addition, Giora and Fein (1999b) conducted a study to investigate people's understanding of familiar ironies such as very funny and less familiar ironies such as thanks for your help. These were compared to their literal uses in supporting contexts. Participants did a timed lexical decision task for target words which were either literal (e.g., useful) or ironic (e.g., angry). For less familiar ironies, the responses were faster to the literal target when the latter was presented for a shorter period of time. In contrast, expressions with both salient literal and ironic interpretations such as very funny had similar processing times when targets were presented either in a short or long period of time (milliseconds) and when context to support either interpretations were presented. This suggests that the information on salience was primarily used before context or literality.

Williams (1992, as cited in Giora, 2002), has also found that the salient literal and figurative meanings were both activated at the initial stage in the processing of familiar metaphors. As an example, the polysemy firm, whose literal and metaphoric meanings are salient, had equivalent processing advantage when presented in either contexts: a metaphor-supporting context the school teacher was criticized for not being firm, and a literal-supporting context the couple wanted a bed that was firm. Finally, Katz and Ferretti (2001, as cited in Giora, 2002) showed that familiar proverbs and their familiar literal uses had equal reading times.

The finding of similar activation for both the salient literal and figurative meanings of the idioms are thus incompatible with claims suggesting that literal meanings do not need to be activated at all in idiom processing (Gibbs, 1984). Similarly, it cannot justify the existence of a separate mental list for storing the figurative meanings of idioms (Bobrow \& Bell, 1973; Swinney \& Cutler, 1979). The hypothesis advocating the advantage of literal over idiomatic analysis in the "idiom list hypothesis" (Bobrow \& Bell, 1973), in particular, does not seem to match the results from the present study in which both meanings were activated 
simultaneously. In addition, the results also fail to suggest the existence of a different processing mode for figurative language. Since immediate activation was found for both literal and figurative meanings as opposed to after a certain delay, the result is not consistent with Cacciari and Tabossi's (1988) claim of an "idiomatic key" determining meaning access. More importantly, based on the GSH (Giora, $1997,2003)$, it is asserted that literality does not govern direct access to the mental lexicon. Therefore, based on the findings of the present study, salience should be deemed as the determining factor for the activation of idiom meaning and not literality.

Based on our literature search, this study could be the first to investigate idiom processing involving language items in the Malay language. Despite this, the researcher acknowledges possible limitations in terms of item validity due to the lack of extensive databasing for these items. Therefore, a post analysis involving the target words in particular was done as they were not selected from any familiarity database (due to unavailability). Also, in support of the claim of a balanced salience, there was a need to investigate the familiarity levels of the literal and idiomatic targets, and ultimately to ascertain that both targets are of high familiarity levels. However, the post investigation was done based on Yap et al.'s (2010) database for printed frequency (how often words appear in one local newspaper) which may not be an accurate measurement of familiarity or salience. Most word-pairings were found to have a large "frequency" (million) gap between them such as for the pair target cuti-sejuk (vacation-cold) with a frequency difference of 110.75 million. Since the results were too varied and difficult to conclude, no further conclusion was made. As a whole, it was thus concluded that research in the areas of language processing for Malay items can certainly benefit from the creation of word databases covering more psycholinguistic norms such as familiarity rating and meaningfulness to account for item validity. Finally, it is important to note that in the present study, context was deliberately excluded from the presentation of idiomatic stimuli, unlike many of Giora's (1997, 2002, 2003; Giora \& Fein, 1999a) studies claiming the secondary role of context.

\section{Conclusion}

In this study, similar processing speeds were recorded for native responses to both the literal and idiomatic meanings of familiar Malay idioms or simpulan bahasa. This shows that salience or familiarity has a dominating effect in the processing of familiar idioms over literality in the absence of context. This lends further support to the claim of modularity in lexical access based on salience hierarchy in the mental lexicon as asserted by the Graded Salience Hypothesis (Giora, 1997, 1999, 2002). The L1 data from this study may therefore serve as preliminary evidence and knowledge for further investigation on cognitive processes in the reading or comprehension of figurative language by native speakers of Malay. This is particularly important because experimental studies in the field of linguistics, psychology, and the social sciences, have until quite recently been dominated by researchers and experimental populations from "WEIRD" societies: Western, Educated, Industrialised, Rich, and Democratic (Henrich, Heine, \& Norenzayan, 2010, 
as cited in Eisenbeiss, 2014). Clearly, basic psycholinguistic knowledge pertaining to language databasing is still very limited for Malay language items and provides potential room for further research. Consequently, the present study may serve to encourage more experimental research to be carried out in the field of psycholinguistics that involves Malay and other languages in the broader Austronesian family.

\section{Acknowledgement}

We would like to express our gratitude to Universiti Malaysia Sarawak for funding this project under its Small Grant Scheme (03(S110)/882/2012(23)).

\section{Reference}

Abd. Rahman, K., \& Mohd. Norwawi, N. (2013, May). Proverb treatment in MalayEnglish machine translation. Paper presented at the $2^{\text {nd }}$ International Conference on Machine Learning and Computer Science, Kuala Lumpur, Malaysia.

Abel, B. (2003). English idioms in the first language and second language lexicon: A dual representation approach, Second Language Research, 19(4), 329-358.

Batemanazana, V., Jaafar, A., \& Salehuddin, K. (2014). A comparative study on the eye movement patterns in Malay-English bilingual readers. Procedia - Social and Behavioral Sciences, 118, 229-234.

Bobrow, S., \& Bell, S. (1973). On catching on to idiomatic expressions. Memory and Cognition, 1, 343-346.

Cacciari, C., \& Tabossi, P. (1988). The comprehension of idioms. Journal of Memory and Language, 27, 668-683.

Charteris-Black, J. (2002). Second language figurative proficiency: A comparative study of Malay and English. Applied Linguistics, 23, 104-133.

Charteris-Black, J. (2003). A prototype-based approach to the translation of Malay and English idioms. In S. Granger, J. Lerot, \& S. Petch-Tyson (Eds.), Corpus Based Approaches to Contrastive Linguistics and Translation Studies (pp.123140). New York, NY: Rodopi B.V.

Cieślicka, A. ( 2006). Literal salience in on-line processing of idiomatic expressions by second language learners. Second Language Research, 22, 115-44.

Cooper, T. C. (1999). Processing of idioms by L2 learners of English. TESOL Quarterly, 33(2), 233-262.

Daud, I. (2001). Peribahasa dan amalan negatif. Dlm. Pelita Bahasa (hlm. 16-17). Kuala Lumpur: Dewan Bahasa dan Pustaka.

Eisenbeiss, S. (2014, September). Extending experimental linguistics to underresearched languages and populations - the principle of justice and new ethical challenges. Proceedings for the "2nd annual national convention on ethics in research on human subjects: Evolving norms and guidelines for the Indian context", Institutional Ethics Board, India. Convention Centre, JNU. 
Ghareeb-Ali, Z. (2008). On-line idiom processing by second language learners of English. Unpublished master's dissertation. University of Essex, Colchester, UK.

Gibbs, R.W. (1980). Spilling the beans on understanding and memory for idioms in conversation. Memory and Cognition, 8, 149-156.

Gibbs, R.W. (1984). Literal meaning and psychological theory. Cognitive Psychology, 8, 191-219.

Gibbs, R. W. (1986). On the psycholinguistics of sarcasm. Journal of Experimental Psychology, 115, 3-15.

Gibbs, R.W. (2002). A new look at literal meaning in understanding what is said and implicated. Journal of Pragmatics, 34, 457-486.

Gibbs, R. W., Wilson, N. L., \& Bryant, G. A. (2012). Figurative language: Normal adult cognitive research. In M. Spivey, K. McRae, \& M. Joanisse (Eds.), The Cambridge handbook of psycholinguistics (pp. 465-484). New York, NY: Cambridge University Press.

Giora, R. (1997). Understanding figurative and literal language: The graded salience hypothesis. Cognitive Linguistics, 7, 183-206.

Giora, R. (1999). On the priority of salient meanings: studies of literal and figurative language. Journal of pragmatics, 31, 919-929.

Giora, R. (2002). Literal vs. figurative language: Different or equal? Journal of Pragmatics, 34, 487-506.

Giora, R. (2003). On our mind: Salience, context and figurative language. Oxford, UK: Oxford University Press.

Giora, R., \& Fein, O. (1999a). On understanding familiar and less-familiar figurative language. Journal of pragmatics, 31, 1601-1618.

Giora, R., \& Fein, O. (1999b). Irony: Context and salience. Metaphor and Symbol, 14, 241-257. Retrieved from http://www.tau.ac.il/ giorar/files/giora.fein.99.irony.pdf

Giora, R., Fein, O., Laadan, D., Wolfson, J., Zeituny, M., Kidron, R., . . Shaham, R. (2007). Expecting irony: Context vs. salience-based effects. Metaphor and Symbol, 22(2), 119-146.

Hassan, A., \& Mohd, A. (1993). Kamus Peribahasa Kontemporari ( $3^{\text {rd }}$ ed.). Kuala Lumpur: PTS Professional Publishing.

Henrich, J., Heine, S. J., \& Norenzayan, A. (2010). The weirdest people in the world? Behavioral and Brain Sciences, 33(2-3), 61-83.

Jalil, S., \& Rickard Liow, S. J. (2008). How does home language influence early spellings? Phonologically plausible errors of diglossic Malay children. Applied Psycholinguistics, 29(4), 535-552.

Katz, A. N., \& Ferretti, T. R. (2001). Moment-by-moment comprehension of proverbs in discourse. Metaphor and Symbol, 11, 17-37.

Lee, L. C., Rickard Liow, S. J., \& Wee, M.-L. O. (2007). Morphological structure of Malay: Using psycholinguistic analyses of rated familiarity. In M. Alves, P. Sidwell \& D. Gil (Eds.), SEALS VIII Papers from the 8th Annual Meeting of the Southeast Asian

Linguistics Society 1998 (pp. 109-119). Canberra, Australia: The Australian National University. 
Lim, K. H. (2003). Budi as the Malay mind: A philosophical study of Malay ways of reasoning and emotion in peribahasa. Unpublished doctoral thesis. University of Hamburg, Germany.

Ishak, N. S., \& Mansor, M. M. (2011, November). Peribahasa: Gambaran minda Melayu dalam penciptaan iklan. Kertas kerja dibentangkan di Seminar Antarabangsa Linguistik dan Pembudayaan Melayu VII (SALPBMVII), Universiti Putra Malaysia, Serdang, Malaysia.

Mat Hassan, A. F. \& Hamzah, Z. A. Z. (2010). Pengkategorian peribahasa Melayu berdasarkan aspek nilai dan pemikiran: Satu analisis pragmatik. Selangor, Malaysia: Universiti Putra Malaysia.

Mohd Amin, N., Meor Hissan, W. S., \& Abdul Rahman, N. A. (2013). It takes two to 'tangle' for Malay idioms, but does it also take 'two' to learn them? International Proceedings of Economics Development \& Research, 74, 69-74.

Nunberg, G. (1978). The pragmatics of reference. Bloomington, IN: Indiana University Linguistics Club.

Pareira, V., Rickard Liow, S. J., \& Mohd Saniff, S. (1992). Familiarity ratings for 530 Malay words. Working Paper No. 42, Department of Social Work and Psychology, National University of Singapore.

Mohamad Deli, R., Kamil, S. M., Mustafa, R., \& Sarbini-Zin, M. (2013, December). Compositionality and familiarity rating of Malay idioms for research on figurative language. Paper presented at the Memory Conference Network, Universiti Kebangsaan Malaysia, Bangi, Malaysia.

Mohamad Deli, R., Mustafa, R., \& Sarbini-Zin, M. (2012). Word familiarity and lexical change: The case of Sarawak Malay dialect. Issues in Language Studies, 1(2), 17-23.

Salehuddin, K. (2013). Arabic script of written Malay: Innovative transformations towards a less complex reading process. Pertanika Journal of Social Sciences and Humanities, 21(S), 63-76.

Salehuddin, K. \& Winskel, H. (2015). Experimenting different Jawi spelling conditions to gauge their cognitive complexity. GEMA Online Journal of Language Studies, 15(2), 51-63.

Salleh, M. R. (1999). Peribahasa dalam masyarakat Melayu satu analisis pemikiran dan cerminan falsafah. Selangor, Malaysia: Universiti Putra Malaysia.

Swinney, D. A., \& Cuttler, A. (1979). The access and processing of idiomatic expressions. Journal of Verbal Learning and Verbal Behaviour, 18, 523-534.

Tittone, D.A., \& Connine, C. M. (1999). On the compositional and noncompositional nature of idiomatic expressions. Journal of Pragmatics, 31, 1655-1674.

Van de Voort, M. E. C., \& Vonk, W. (1995). You don't die immediately when you kick an empty bucket: A processing view on semantic and syntactic characteristics of idioms. In M. Everaert, E.-J. Van der Linden, A. Schenk, \& R. Schreuder (Eds.), Idioms: Structural and psychological perspectives (pp.283-300). Hillsdale, NJ: Lawrence Erlbaum.

Weinreich, U. (1969). Problems in the analysis of idioms. In J. Puhvel (Ed.), Substance and structure of language (pp. 23-81). Berkeley, CA: University of California Press.

Williams, J. N. (1992). Processing polysemous words in context: Evidence from 
interrelated meanings. Journal of Psycholinguistic Research, 21, 193-218.

Yap, M. J., Rickard Liow, S. J., Jalil, S., \& Faizal, S. S. (2010). The Malay Lexicon Project: A database of lexical statistics for 9,592 Words. Behavior Research Methods, 42, 992-1003.

Zahid, I. (1998). Peribahasa Melayu: Satu klasifikasi yang tiada penentu. Jurnal Dewan Bahasa, 42(11), 978-984. 